\title{
The Creativity Literary of Gongora
}

\section{Assistant Instructor: Ahmed Abdulrazzaq Al-Rubaiee Assistant Instructor: Habeeb Abdulsattar Jabbar Alimam Al-Adam University college}

\section{Abstract:}

Luis de Góngora y Argote, (1561-1627), Spanish poet, is one of the most influential Spanish poets of his era. His Baroque, convoluted style, known as Gongorism was so exaggerated by less gifted imitators that his reputation suffered after his death until it underwent a revaluation in the 20th century.. In his literary works has expressed very well his feelings and emotions perfectly, especially the thought of his time and the themes of criticism and disappointment of the Baroque. His poetic work breaks molds and inaugurates a new language whose virtuality, still unsurpassed, continues to mark the course of contemporary poetry. This investigation is divided in two chapters, the first presnte the biography and style of Gongora besides its works that comprise the satire. The second chapter is concerned Cultism and gonorismo, besides the Architecture of the sonnets of Góngora.

\section{إبداع غونغورا الأدباي

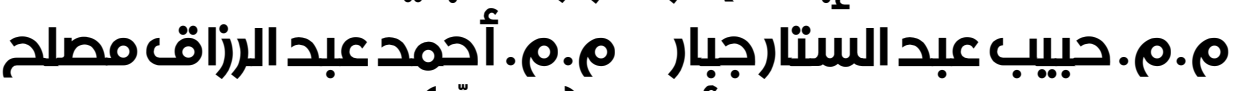 كلية الإمام الأعظم (رحمه اللّه) الجامجامة}

الملخص:

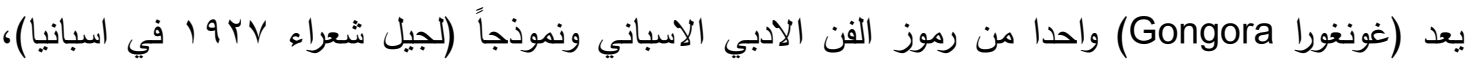
خلال مسيرته الادبية كتب عدة اشعار ومسرحيات ذات مواضيع تقليدية شعبية مكوناً في ذلك لوحة عن شخصيته الطيبة والغامضة يمتاز بأسلوب التصنع والبديع في الاعمال الادبية وهذا واضح في عمله الموسوم (اسطورة بوليفيمو

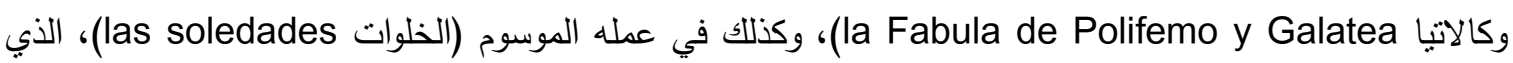
يصل فيها إلى قمة غموضه الثديد في (أسلوب الباروكو) .ان ذلك الغموض كان أسلوبا فنباً خاصاً بقصائد تلاك

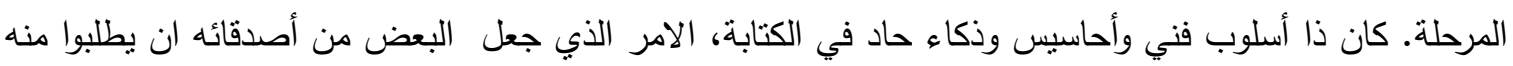
أن يبذل أو يلغي بعض التراكيب اللغوية في أعماله وذلك لأسلوبه الادبي الغامض لقد كان غونغور الاهر واحدا من

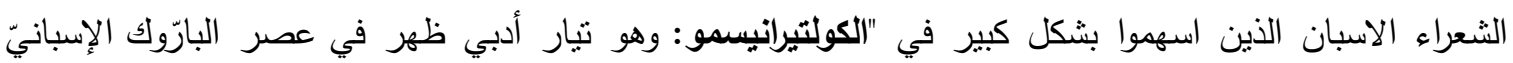
ويستخدم الألفاظ النقيلة والاستعارات الخالصة والتلميح عبر الأساطير القديمة. ويعرف هذا التيار الجمالي أيضاً باسم

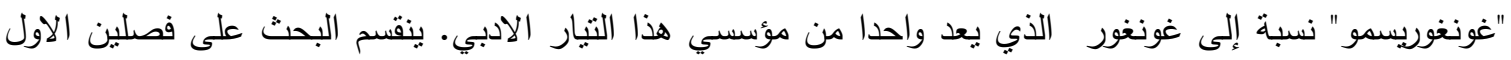

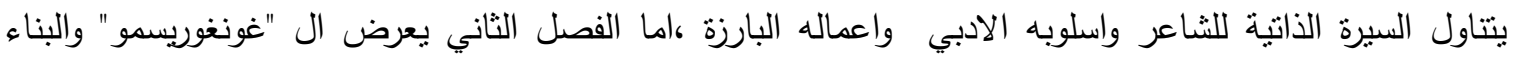

\section{Introducción:}


Luis de Góngora y Argote, (1561-1627), poeta español, cima de la elegancia de la poesía barroca y modelo de poetas posteriores. Góngora tuvo en vida defensores apasionados y críticos implacables. En sus obras literarias ha expresado muy bien sus sentimientos y emociones perfectamente, sobre todo el pensamiento de su tiempo y los temas de crítica y desengaño del barroco. Su obra poética rompe moldes e inaugura un nuevo lenguaje cuya virtualidad, aún insuperable, sigue marcando rumbos en la poesía contemporánea.

Esta breve investigación se divide en dos capítulos, el primer capítulo trata de la biografía y estilo de Góngora además de sus obras que comprenden la sátira.

En cuanto al segundo capítulo estudia el Cultismo y el gongorismo, además de la Arquitectura de los sonetos de Góngora.

\section{I.1- Biografía de Góngora}

Nació en Córdoba, en 1591.Su padre, don Francisco de Argote, licenciado por Salamanca, ejercía en aquella ciudad de Juez de bienes confiscados de la Inquisición, tenía aficiones eruditas y poseía una copiosa biblioteca. Su madre se llamaba doña Leonor de Góngora y, como su esposo, pertenecía a ilustre familia cordobesa. El escritor prefirió anteponer el apellido de su madre, quizá por más sonoro, y así vino a llamarse Luis de Góngora y Argote. Muy poco se conoce de su niñez y primeros estudios. A los quince años fue enviado a estudiar en Salamanca. Un hermano de su madre, don Francisco de Góngora racionero de la catedral de Córdoba, para ayudar en los estudios del muchacho le cedió los beneficios eclesiásticos que tenía en diversos pueblos, y Góngora recibió, para poderlos disfrutar, las ordenes menores. Se matriculó de Cánones en Salamanca en 1576 y siguió hasta el curso 79-80, pero no consta que obtuviese título alguno. Debió de estudiar muy poco pero en aquellos años estudiantiles cuajo su vocación de poeta. De 1580tenia diecinueve años-son sus primeras composiciones conocidas, y a dicha fecha pertenecen también sus primeros versos impresos: una canción, toda en esdrújulos, que figura al frente de la traducción castellana de Os Lusiadas, hecha por Luis de Tapia. La fama de Góngora como poeta debió de cundir rápidamente: en 1584 Juan Rufo colocaba al frente de su Austriada un soneto de Góngora, y el año siguiente Cervantes hacía un gran elogio en el Canto de Calíope incluido en la Galatea ${ }^{1}$.

Prosiguiendo en su protección, su tío don Francisco renunció en el joven poeta su cargo de racionero, y Góngora recibió las órdenes mayores. No

1 Angel Valbuena Part, Poesía del Renacimiento y el Barroco, Editorial Gustavo

Gili,S.A. Barcelona, 1981.pags.78-79. 
debía de ser muy celoso en el cumplimiento de sus deberes eclesiásticos, porque el Nuevo Obispo llegado a Córdoba en 1587 le amonesta por su falta de asistencia al coro, y cuando-añade-"anda de acá para allá saliendo con frecuencia de silla " y habla mucho durante los oficios; en le ve con frecuencia en espectáculos profanes-toros, comedias-y en tertulias de maldicientes, "vive como muy mozo", trata en cosas ligeras y escribe coplas profanes. Góngora se defendió con mezcla de gracia y desenfado, diciendo que en el coro podía hablar mucho porque estaba entre un sordo y uno que no dejaba decantar; y que no siendo Viejo, no podía vivir sino como mozo; que a los toros no había ido sino unas pocas veces; y que si en sus coplas había tenido alguna libertad, su poca teología lo disculpaba y, en todo caso, había tenido por mejor 'ser condenado por liviano que por hereje". El Obispo le impuso una pequeña multa y le prohibió que fuera a los toros.

Desde entonces, y a lo largo de vario anos, alterna el cultivo de la poesía con viajes a distintos lugares de España comisionado por su cabildo. Une serie do composiciones, en especial sonetos, conservan el recuerdo de su paso por estas ciudades. En 1603 estuvo en Cuenca, de cuya visita nos ha quedado uno de sus más bellos romances.

\section{En los pinares del Xucar}

Vi bailar unas serranas,

Al son del agua en las piedras,

$Y$ al son del viento en las ramas... ${ }^{2}$.

Y en Valladolid, donde, residía entonces la Corte. A su regreso a Córdoba, que demoró cuanto pudo, dejó a Pedro Espinosa el texto de las poesías que este había de incluir en su Flores de portas ilustres, publicadas en 1605.Nuevos viajes por España, y nuevas composiciones que nos conservan su recuerdo. En 1610 tiene lugar la toma de Karache, y Góngora le dedica una canción, que 1610 tiene lugar la toma de Larac he,y Góngora le dedica una canción, que suele tomarse como el arranque de la llamada "segunda época". En 1611 nombra a un sobrino suyo coadjutor de su cargo en la catedral cordobesa, con lo que queda libre de la asistencia a coro.

Poco después comienza a trabajar en la redacción de sus más ambiciosos poemas, la Fábula de Polifemo y Galatea y las Soledades, y en mayo de 1613 se leen en tertulias literarias de Madrid algunos fragmentos del primero. Góngora, que desde sus primeros viajes a la Corte había acariciado la ambición de establecerse en ella, lo consigue en 1617 gracias al favor del primer ministro, el fugue de Lerma, a quien dedica su Panegírico, otras de sus obras de grandes proporciones; también por su mediación es nombrado capellán de su Majestad, para lo cual se ordena de sacerdote a los cincuenta y cinco años.

${ }^{2}$ Ángel Valbuena Part. Historia de literatura española, Editorial Gustavo Gili, S.A. Barcelona, 1963.Pags.122-125. 
La caída de sus valedores políticos a la muerte de Felipe III y sus grandes gastos en la corte, agravados por su afición al juego, tuvieron a Góngora en constante dificultad, que trató de remediar ganándose el favor del nuevo más aparente que efectiva. Una enfermedad que le aquejaba desde antiguo, acabo de amargar sus últimos años en Madrid; había perdido la memoria y sufría frecuentes desvanécenos y Fuertes Dolores de cabeza. Aprovechando una ligera mejoría, regresó a Córdoba, donde acabo sus días, a los sesenta y seis años de edad, en mayo de 1627.

Góngora no sólo es, con Lope de Vega y Quevedo, uno de los tres mayores poetas de la España de su época .Es el poeta por excelencia. Por vivas que hayan sido las controversias que suscito su obra en vida del poeta, por asombrosas que hayan podido ser las vicisitudes que sufrió en el curso de los siglos, su preeminencia se impone en adelante indiscutiblemente. Modelado por la cultura, alimentado por múltiples tradiciones, no por eso deja ser el inventor de una "nueva poesía" que, por la virtud de un lenguaje de una plenitud absoluta la esencia misma de las cosas y exalta el mundo recreándolo.

Esta aventura excepcional, con la distancia del tiempo, nos hace el efecto de una gravitación solitaria; y, sin embargo, se inscribe en un paisaje tan rico como variado. La España del siglo XVII cultivó la poesía con pasión, más allá del círculo de los profesionales de las letras. Pudo, a veces, dividirse entre del circulo de los profesionales de las letras. Pudo, a veces, dividirse entre admiradores y adversarios de esa "poesía nueva", de la que Góngora se había convertido en el símbolo; pero, como veremos, la abundante producción que nos ha dejado, y que estamos lejos de haber recorrido por entre en escapa a las clasificaciones y compartimentaciones que se le quiso imponer en otra época. A falta de captar su exacta medida, trataremos, llegado el momento, de distinguir sus principales rasgos a favor de una rápida Mirada ${ }^{3}$.

\section{I.2.las poesía lírica en la época de Góngora}

A partir de 1580 y hasta mediados del siglo XVII, se asiste en España a un notable florecimiento de la poesía lírica; entendemos con este término, como lo hizo el siglo XVII, toda la poesía con exclusión de los poemas épicos y los pomas dramáticos. Esta masa de textos están lejos de estar totalmente catalogado. Colecciones manuscritas e impresas plantean, en efecto, innumerables problemas de transmisión, de atribución y de datación que falta de estar resueltos, imponen la mayor prudencia a quien quiere intentar clasificar esta abundante producción. Se impone al menos una evidencia: el florecimiento continuo y multiforme de esta poesía (sonetos, canciones, romances, letrillas, decimas, epístolas, fábulas mitológicas, etc.) es particular

\footnotetext{
${ }^{3}$ Ibíd. Pag. 125
} 
espectacular en ciertos centros: Madrid, Zaragoza, Toledo, Valencia, Granada, Antequera, Córdoba y, por supuesto, Sevilla, polo financiero de la Península ${ }^{4}$.

Esta focalización de la vida literaria es lo que explica la tendencia de la crítica, sobre todo en el siglo XIX a clasificar los poetas por escuelas regionales y atribuir a cada una de esas escuelas (sevillana, granadina, aragonesa, etc.) características propias, lo que no ha dejado de desembocar en una sistematización insostenible. La otra tendencia, aún más discutible, consiste en repartir a esos escritores en dos batallones rivales: los "cultistas", agrupados en torno a Góngora y los "anticultistas", discípulos de Lope de Vega y alados a los "conceptistas", seguidores de Quevedo..Esta clasificación, cuyo origen se remonta a las polémicas que desencadenaron las Soledades ,no resiste el examen: los poetas cuyo estilo no debe nada a Góngora (conde de Salinas, Arguijo, príncipe de Esquilache, etc.) fueron a menudo sus más fervientes admiradores y a la inversa. Buscar este tipo de fronteras en el siglo XVII es un anacronismo. La breve visión que sigue excluye, además de Góngora, a Lope y Quevedo, cuyas obras poéticas se estudian aparte. Escritores severos y respetables, los dos hermanos Leonardo de Argensola sólo consagran, si bien se mira, una parte mínima de su actividad a la creación poética ${ }^{5}$.

\section{I.3. Estilo de Góngora}

Durante mucho tiempo se ha partido de la base de dos estilos o maneras de Góngora, una clara, sencilla, popular; otra que se consideraba oscura, culta, retorcida, hinchada. No basta sólo con rehabilitar el Segundo estilo o "culteranismo" ; hoy, con los estudios de Artigas y Dámaso Alonso, especialmente, se advierte que no hay dos épocas cerradas, en que se dan el estilo popular, primero; el culto, después; sino más bien dos líneas paralelas, primero; el culto, después; sino más bien dos líneas paralelas, que en un determinado momento tienen ,una u otra, más relieve e importancia, pero sin perderse la continuidad. Dámaso Alonso en un estudio hondo sobre el estilo de Góngora, advierte (aunque acaso con exceso de exageración) cómo en un romance que tradicionalmente ha sido juzgado como sencillo y popular, hay no pocas dificultades de interpretación, paralelismos y riqueza decorativa propios del Segundo momento del poeta. La frase de Cáscales, del Góngora príncipe de luz y príncipe de tinieblas, paralela al fondo de claroscuro con que el discípulo de Velázquez) diseño el rostro del poeta, debe pues mirarse hoy con mucho cuidado. Los estilos de Góngora, como los dos del Greco o los de Calderón, no son formas independientes sino llenas de interferencias. Un soneto culto, como el dedicado a El Escorial tiene que ser anterior a 1598,

\footnotetext{
4 Juan Luis Alborg, Historia de la literatura española Edad Media Y Renacimiento, Editorial Gredos, Madrid, 1982.Pag 88.

${ }^{5}$.Ibíd.Pag.90
} 
pues habla de Felipe II, como personaje vivo; en cambio, letrillas y romances siguen produciéndose en los últimos años del poeta. En el estilo artisticpopular, como podría llamarse al tradicionalmente primero, predominan las formas de metro corto, letrillas, en endecha, romances, letras para cantar octosilábicas.. En las endechas primeras hay una cierta emoción lirica, que se sustituye después por una mayor riqueza decorativa; a éste momento de formas de poesía casi desnudas corresponde la sentida letrilla "Dejadme llorar- orillas del mar" y el simpático y emocionado recuerdo pintoresco infantil "Hermana Marica". En otro romance corte, en que se alude a este-"al que hizo", la "Hermana Marica"-, se nos ofrece un interesante retrato del poeta, aunque envuelto en rasgos paródicos' "abierto de sienes, cerrado de encías", frente ancha, ojos grandes, nariz corva, aguileña, estatura mediana, hombres y espalda anchos. Mozo alegre, pero sin que le falten toques melancólicos. Entre las muchas letrillas satíricas es una de las más perfectas y desahogadamente epicúreas la de "Ande yo caliente". En otras la malicia punzante de Góngora no retrocede ante las mayores procacidades ${ }^{6}$.

A las formas más finas y delicadas de este comentador de letras para cantar corresponden "Las flores del romero", "Aprended, flores, de mí" y todo "No son todos ruiseñores", cuyos versos toreados y sugerentes, como en las imágenes del violín que vuela y la lira inquieta, son de lo más exquisita del artista de las formas más bellas de la lírica española. Los romances ofrecen variado aspectos del lirico cordobés. Notemos cómo entre los tres mayores cultivadores de esta forma tradicional, en el final del siglo XVI comienzos del XVII, Góngora representa el mayor cuidado de la forma, la más fina poetización de tema y detalles, los versos más limados y sonoros; tendía Lope a envolver en artificio los motives de emoción o dejar correr libre esta, en los temas religiosos; y Quevedo dedicaba este metro a los conceptuosos chistes en torno a motives del hampa picaresca. Aunque Góngora cultiva el romance caricatural, la parte más saliente en este género se debe a diáfanas adquisiciones en diversos grupos. En alguno, el lazo las "letras para cantar" es evidente. El romance viene a server de cuadro descriptivo para la copla musical, como en uno de los ejemplos más bellos y ricos ${ }^{7}$.

\section{I.4. Cultismo y gongorismo}

Es necesario que distinguir con claridad entre "cultismo literario' y "gongorismo". Como llevamos visto en repetidas ocasiones, la corriente culta en literatura es una fuerza que se inicia con el mismo alumbrar del Renacimiento. Su meta es la imitación de los escritores de la antigüedad

\footnotetext{
${ }^{6}$ www. brendaortiznevarez.aprenderapensar.net. Consultado el 10-10-2016.

${ }^{7}$ Ibíd.
} 
grecolatina: imitación en los géneros, en los temas, en el léxico (de donde procede la inundación de voces cultas), en la sintaxis, en las metáforas mitológicas, etc. Esta corriente arranca propiamente de Petrarca y produce la gran marea petrarquista con la que está implicado el desarrollo de todo el Renacimiento europeo. Por lo que a España concierne, después del importanteaunque frustrado- anticipo del siglo $\mathrm{XV}$, el movimiento culto triunfa en la primera mitad del siglo XVI y se robustece con creciente intensidad en la segunda parte de la centuria; movimiento que, por lo demás, corre a la par por todas las naciones de Europa. Insistimos en estas ideas, ya anteriormente expuestas, para puntualizar el hecho de que Góngora nace a la literatura en plena atmósfera culta, cuando los gustos literarios avanzaban en el sentido de una intensificación creciente del cultismo, dentro del cual, y a lo largo de su vida, era desarrollando es, pues, una manifestación particular del cultismo literario prevalente y creciente es, pues, una manifestación particular del cultismo literario prevalente y creciente en España (y en Italia y en gran parte de Europa)en el siglo XVI y en el XVII, Góngora, en consecuencia, no es en manera alguna un fenómeno extraño que se produzca en la literatura de su época como una excrecencia caprichosa, sin solidas razones y profundas raíces, sino como coronación de todo un proceso. Por esto mismo, la "material poética" digamos, con que Góngora forja sus propios versos, no difiere en absoluta de la utilizada por los otros poetas que forman la cadena hasta él; con ningún elemento sustancialmente nuevo. Su personalidad está hecha de sumas, de acumulación, de intensificación, llevadas hasta la última sutileza: "poesía límite ${ }^{8}$.

\section{II.1.Los Cultismos}

La primera condición que destaca en el estilo de Góngora es el frecuentísimo uso de voces cultas; sus enemigos-contemporáneos y posteriores reprochan el haber tomado directamente del latín un torrente de palabras extravagantes, completamente desusadas en el español literario de la época. Dámaso Alonso sostiene, sin embargo, que "lo único que hizo Góngora fue popularizar, difundir, una serie de vocablos, de los cuales la mayor parte eran ya usados en literatura y habían conseguido entrada en los vocabularios de la época, y sólo los menos en realidad una minoría reducidísima podían ser considerados de como raros, aunque aun estos estaban implícitos en la fórmula general de su arte), Góngora no inventa; recoge, condensa, intensifica: ése es su papel. Dámaso Alonso demuestra a continuación-y a este estudio remitimos al lector-que muchos de los cultismos gongorinos habían sido empleados ya en la Edad Media, algunos durante los primeros siglos literarios, muchos más en el siglo XIV y sobre todo a lo largo del XV; que abundantes cultismos gongorinos figuran ya en

\footnotetext{
${ }^{8}$ www://html.rincondelvago.com/gongora-y-el-culteranismo.html. Consultado el 12-10-2016.
} 
Nebrija (son los más antiguos y asimilados por la lengua); y que casi todos los restantes van entrando en los diccionarios-las Casas, Percival, Palet, Covarrubias-entre 1570 y 1611. Lo que produjo, en cambio, la irritación de los contemporáneos no fue el uso de voces empleadas ya o a punto de aclimatarse en castellano, sino el abuso de su repetición y su agrupamiento dentro de un poema. Y fue esto, a su vez, lo que facilitó las parodias de los enemigosEl cultismo para Góngora no es una mera cobertura externa, sino que forma parte de su intento de creación-dentro de las más genuinas teorías renacentistas de un lenguaje poético, y es, por tanto, "algo que impregna toda la masa de su concepto poético del mundo de su calidad de idioma imperial y su posibilidad de parangonarse con el latín que, inevitablemente, se toma como modelo y se calca su léxico y sintaxis ${ }^{9}$.

En la creación de esa lengua imperial y universal, noble y Sonora, el cultismo al igual de todos los restantes elementos poéticos tienen una función primordial: podemos decir "que es la elusión de la palabra desgastada en el comercio idiomático y su sustitución por otra que abre también una ventana sobre un mundo de fantástica coloración: el mundo de la tradición grecolatina .El cultismo gongorino tiene, pues, un valor expresivo, desempeña una función idiomática .No es una pesada e indigesta carga de pedantería, como han guarido generalmente los manuales de literatura. En Góngora, en el siglo XVII, está justificado por una larga tradición, pero sobre todo está justificado por ser una necesidad de expresión esencial a la concepción poética del gran cordobés. Suprímasela quedaría destruida toda la estructura arquitectónica, toda la regulación cósmica del sistema gongorino. No es un defecto, es un valor positivo de la poesía de Góngora ${ }^{10}$.

\section{II.2.La Sintaxis gongorina}

El propio Dámaso Alonso, al tratar de negar las diferencias entre las "épocas" de Góngora, admitía en la segunda la existencia de una mayor acumulación de dificultades sintácticas y de hipérbaton, que se traducía en una multiplicada dificultad. Procede esta no "de los atrevimientos sintácticos aislados', sino de su frecuencia y entretejimiento. Estos apenas son posibles en las composiciones breves o en los metros cortos, pero encuentran campo propicio en las largas; de aquí que tengan sumas exacerbada manifestación en el Polifemo y más todavía en las Soledades. Imposible sintetizar siquiera aquí los problemas sobre el hipérbaton en nuestro idioma. Apuntemos tan sólo que su evolución sigue en línea paralela a la del cultismo; la enorme libertad del español para el orden de las palabras-superior a la de todas las otras lenguas románicas-se acentuó tras el deseo de emular al latín y elevar la dignidad y

\footnotetext{
${ }^{9}$ Diego Martín, Breve historia de la literatura español, Editorial Octaedro, 1966.Pag.89.

${ }^{10}$ Ibíd.Pag.92
} 
posibilidades expresivas del lenguaje literario. El hipérbaton, repetimos, vino a ser una faceta más del estilo culto, y llega a Góngora tras el mismo proceso y avatar que los cultismos léxicos. Baste decir aquí que Góngora sigue un proceso intensifícatelo del hipérbaton a lo largo de su producción, hasta llegar en sus grandes poemas a producir las innegables dificultades que de siempre le han reprochadas. Esto no obstante, Góngora fue un maestro en el arte de servirse del hipérbaton par a las más delicadas posibilidades expresivas: "En sus manos -dice Dámaso Alonso-fue un instrumento apto que, muchas ocasiones, sirve para dar flexibilidad y soltura a la lengua, permite el aéreo encadenamiento de un período, aquí facilita un donaire o una momentánea alusión, allá un efecto imitativo, a veces hace resaltar el valor eufónico o colorista de una palabra, permitiendo su colocación en un punto donde el ritmo tiene su cima de intensidad, otras hace surgir nítido, de punta en blanco, un espléndido verso ${ }^{11}$.

\section{II.3. La Arquitectura de los sonetos de Góngora}

Uno de los aspectos de más realce artístico de la lírica de Góngora se halla en su magnífica y variada serie de sonetos. El sentido arquitectural, formal, de la composición del soneto es una de las mayores adquisiciones poéticas del "culto cordobés". Góngora, con Quevedo y Lope, representa la cima del soneto en literatura castellana. En este género, cabe aproximar al "primer estilo" el grupo de "burlescos" que poseen fuerza, gracia, concisa y acerada sátira y que penetran en el terreno delo mas malicioso y aun obsceno. Además, sirven de sátira de costumbres o de ambientes y ciudades, alcanzando en este aspecto un valor único -Quevedo llega a otra clase de soneto satírico, por motives, descomunales de caricature-.Otros son sátiras literarias, especialmente contra Lope, y los del "estilo llano" y contra los que censuraban las Soledades.. A veces una nota sucia, rebaja la calidad de esos sonetos, pero tales como son ofrecen un verdadero mérito satírico, como los alusivos al Manzanares, en que se encuentran frases precisas y graficas. Entre las sátiras a personas y familias, uno de los sonetos mejor tramados y de más gracia de expresión es el titulado A una señora de Cuenca, a quien llevó cartas de otras señoras de Córdoba, y le pagó el porte con hacer muestra de unas doncellas suyas. $\mathrm{Si}$ estos sonetos, hermanos de los romances y letrillas satíricas y procaces, denotan a pesar de lo humilde del tema de las cualidades constructivas del poeta, éstas alcanzan un mayor nivel de dignidad en una serie de elogios a personas o ciudades, epitafios o meras descripciones, verdaderos cuadros de un ambiente o una escena. La organización de los materiales poéticos y el desenvolvimiento lógico, ya para quedar constituida una forma cerrada de equilibrio violento pero conseguido, ya para obtener el resultado o consecuencia del terceto o verso final, adquieren un sistema

\footnotetext{
${ }^{11} \mathrm{http}: / /$ bib.cervantesvirtual.com/bib_autor/gongora. Consultado el 2-9-2016.
} 
arquitectónico único en nuestra poesía. Todos estos sonetos lucen esta forma marmórea que utiliza imágenes diáfanas de magnificente belleza y en que la aplicación del estilo "culto" exalta el lugar común a cimas de belleza expresiva. Muchas veces el motive que origina la poesía no puede ser mas mínimo, pero ahí esta la calidad y sentido creador del poeta ${ }^{12}$.

Góngora no hace poesías de encargo, de recreo a base de virtuosismo, sino que la anécdota vulgar se transfigure en tema de deslumbrante sugestión y hermosura. Una vez, el motive lo da la fiesta de toros hecha en Córdoba al paso del Obispo de Sigüenza; otra, el mostrar el Marqués de Ayamonte el retrato de su esposa; la dedicatoria de unos villancicos, la gallería de pinturas de un palacio, los libros de diversas materias que componente sus amigos, ocasionan otros de estos suntuosos sonetos. Qué sugestiva expresión al decir al marques que contempla el retrato de su esposa, ya muerta Entre los elogios de libros, es tal vez el mejor soneto el dedicado a la Historia Pontifical del doctor Babia, comentado incompresiblemente por Luzán, si bien tuvo el mérito de entender el sentido de las imágenes ya que no su belleza; la alusión a eternizar las hazañas de los papas a base de la imprenta, en la imagen final, "que sombras sella en túmulos de espuma" nos parece de lo más bello y diáfano del poeta. Dos, se refieren a la historia de Felipe II de Cabrera: en uno se hallan estos suntuosos versos.

De aquel sí, cuyas hoy cenizas santas,

Breve pórfido sella en paz suave,

Que en poco mármol mucho fénix cabe.

Entre los elogios de personas, uno de los más perfectos es el dedicado a don Antonio Venegas, Obispo de Sigüenza, "Sacre pastor de pueblos que en florida", terminado en magníficos tercetos. Góngora presenta cuadros de viveza y color, en que la arquitectura del poemita cierra los contornos descriptivos, como en la pintura de una fiesta de toros y cajas en Valladolid: "la plaza un jardín fresco, los tablados -un encajado de diversas flores". Todo un cuadro y símbolo de dureza e indiferencia de su época es la descripción de un auto de fe en Granada, en un soneto de perfecta construcción. Bella magnificencia arquitectonica es la resultante de la descripción de una capilla de Toledo-la del Sagrario, de la catedral :

Esta que admira fabrica, esta prima

Pompa de la escultura, oh caminante, En pórfidos rebeldes al diamante ${ }^{13}$

${ }^{12}$ Manuel Gahete Jurado. «Luis de Góngora. El autor». Biblioteca Virtual Miguel de Cervantes. Consultado 13 -10- 2016.

${ }^{13}$ - Ibid. 
En la descripción de edificios es tal vez el ejemplo más bello la de El Escorial" "Sacros, altos, dorados chapiteles- que a las nubes robáis los arreboles": y en los del conjunto y paisaje de una ciudad, el soneto dedicado a su cuna, en que, por extraña excepción al lado de la elegancia formal adquirieren sus versos una calidad de emoción. Al cantar a su Córdoba-"oh excelso muro, oh torres levantadas-de honor, de majestad, de gallardía", asoman a los ojos del poeta, frio como el mármol de sus versos, unas lágrimas de ternura, hechas cristal y diamante. Tras lo satírico, el retrato o memoria y motiva descriptiva queda la gallería de los sonetos de motives de amor más o menos pasionales, pero en que la más fina nota lirica, prescinden de la anécdota y erigen formas cada vez más puras y densas de poesía. Alguna vez, el poeta asocial motives de naturaleza, entre alusiones mitológicas a su ardor en amar, como en la exquisita composición A unos álamos, a los que llama "blanco coro de náyades lascivas"; otra, describe sereno la hermosura formal de una dama con la magnificente delectación del elogio de un edificio o un paisaje, en el sereno y perfectamente organizado poema "De pura honestidad templo sagrado". En otra delicada composición-"Al- tramontar del sol la ninfa mía"-, al presentar a la dama cogiendo flores, movidos del aire sus rubios cabellos, aparece la imagen brillante y dinámica:

\section{El oro fino con error galano,}

Cual verde hoja de álamo Lozano

Se mueve al rojo despuntar del día,

Mientras que otro soneto da una impresión cristalina del tema galante y fino del esclavo de amor:

En el cristal de tu divina mano

De amor bebí el dulcísimo veneno.

Todo un colorista paisaje sirve de base para la evocación de la dama, comparada a la aurora y a las flores, en "Raya, dorado sol, oro y colora ". La vista de la amada borra todo el paisaje exterior; El poeta ante su presencia deja oír a las aves y de mirar las luces del amanecer-"Tras la bermeja aurora el sol dorado"-.Tampoco falta en Góngora el eco del típico motive renacentista del "Collige Virgo rosas" de Ausonio, que ya había inspirado a Garcilaso y Ronsard, a Spenser y Fray Luis de León. Pero Góngora realiza motivas arquitecturales y de medida gradación en dos de sus mejores sonetos; en el estallar de luces y colores, ante el momento vivo de la juventud y la vida "Ilustre y hermosísima María" -:

Antes que lo que hoy es rubio Tesoro

Venza a la blanca nieve su blancura

Goza, goza el color, la luz, el oro;

Y en la mezcla de voluptuosidad y pesimismo, como un abrazo del espíritu renacentista de los cuartetos el medieval de los seis últimos versos, en "Mientras por competir con tu cabello". "Mientras que a cada labio por ello siguen más ojos que al clavel temprano..." dice, hermano en exquisito 
erotismo de Garcilaso y Ronsard, para terminar en el ascético verso que anuncia a Calderón: "en tierra, en humo, en polvo, en sombra, en nada"14.

\section{Conclusión:}

Góngora tenía una gran fama e influencia extraordinaria en el siglo XVII y fue uno de los poetas clásicos y antiguos más importantes en la literatura española, sobre todo, en el Siglo de Oro. El influjo de Góngora llegó a otros autores españoles de su era. Se considera un Poeta cumbre de la poesía castellana, el más original e influyente de la Lirica Española. Su fama fue enorme durante el Barroco. Hay una sensación visual en sus obras poéticas. Utiliza el valor simbólico de las palabras desechando todo término en su acepción real para incorporar al verso únicamente las metáforas.

Sus poesías populares son muy claras, por lo que se denominó a Góngora “ángel de luz”. El carácter innovador de su poesía, cabeza del estilo literario conocido por culteranismo, busca la oscuridad a través de la acumulación de referencias mitológicas, metáforas, hipérboles, juegos de palabras, cultismo y todo tipo de recursos literarios en una lengua de sintaxis complicada, llena de hipérbatos y largas perífrasis dentro de sus obras.

\section{Bibliografia:}

1. Alborg „Juan Luis, Historia de la literatura española: Edad Media Y Renacimiento, Editorial Gredos, Madrid, 1982.

2. Jurado Manuel , Gahete. «Luis de Góngora. El autor». Biblioteca Virtual Miguel de Cervantes. Consultado 13 -10- 2016.

3. Martín, Diego, Breve historia de la literatura español, Editorial Octaedro, 1966.

4. Part ,Angel Valbuena, Poesía del Renacimiento y el Barroco, Editorial Gustavo Gili,S.A. Barcelona, 1981.

5. Historia de literatura española, Editorial Gustavo Gili, S.A. Barcelona, 1963.

6. www. brendaortiznevarez.aprenderapensar.net. Consultado el 10-10-2016

7. www://html.rincondelvago.com/gongora-y-el-culteranismo.html. Consultado el 12-102016.

8. http://bib.cervantesvirtual.com/bib_autor/gongora. Consultado el 2-9-2016.

9. www.hispanismo.cervantes.es/documentos .4-10-2016.

${ }^{14}$ www.hispanismo.cervantes.es/documentos .4-10-2016 